\title{
UMA PROPOSTA DE INTEGRAÇÃO DA TEORIA DAS RESTRIÇÕES COM FERRAMENTAS DO LEAN MANUFACTURING PARA GESTÃO DE PROCESSOS
}

\section{A PROPOSAL FOR INTEGRATION OF THEORY OF CONSTRAINTS WITH LEAN MANUFACTURING TOOLS FOR PROCESS MANAGEMENT}

\author{
Geovanni Geraldo da Silva ${ }^{1}$; Rafael de Carvalho Miranda ${ }^{2}$ \\ ${ }^{1}$ Centro Universitário de Itajubá - FEPI - Itajubá - MG - Brasil \\ geovannisilva707@yahoo.com.br \\ ${ }^{2}$ Centro Universitário de Itajubá - FEPI - Itajubá - MG - Brasil \\ mirandaprod@yahoo.com.br
}

\begin{abstract}
Resumo
Neste trabalho serão discutidos problemas enfrentados diariamente nas empresas, ocasionados por desperdícios e gargalos nos sistemas produtivos. A presença de restrições e desperdícios impedem, em muitos casos, as empresas de atingirem seus objetivos. Nesta situação, duas metodologias de grande importância para o sucesso empresarial e utilizadas pela Engenharia de Produção, podem ser utilizadas para combater estas limitações: a Teoria das Restrições e o Lean Manufacturing. Quando utilizadas de forma conjuntas elas permitem eliminar os desperdícios presentes no sistema, bem como gerenciar de forma eficaz as restrições, fazendo com que as empresas atinjam seus objetivos. Nesse trabalho será realizada uma revisão de literatura, identificando quais as ferramentas do Lean Manufacturing podem auxiliar no processo de implantação de cada um dos passos da Teoria das Restrições. Com a realização deste trabalho, pode-se concluir que ambas as filosofias de produção possuem pontos em comum, podendo assim, contribuírem para o sucesso empresarial de uma organização, quando utilizadas em conjunto.
\end{abstract}

Palavras-chave: Teoria das Restrições; Lean Manufacturing; Ferramentas Lean; Desperdício; Integração.

\section{Introdução}

As empresas atualmente estão à procura de novos métodos que possam aumentar seus lucros e também reduzir o desperdício. Atingindo assim, a melhor excelência em vários fatores, não só em lucros, como também em qualidade, organização e eficiência, para que possam atender as expectativas dos clientes sem terem enormes custos. O que impede muitas vezes uma empresa de chegar aos seus objetivos são as restrições (PERGHER, RODRIGUES e LACERD, 2011).

No processo de fabricação, a restrição é chamada de gargalo, com isso a teoria das restrições fornece um poderoso conjunto de informações para ajudar a alcançar seu objetivo. Esse conjunto é composto por cinco passos de focalização. Através desses passos os gestores tomam decisões para 
garantir o sucesso e até mesmo a sobrevivência da empresa (PERGHER, RODRIGUES e LACERD, 2011).

A Teoria das Restrições (Theory of Constraints - TOC) se resume a um método de identificação e análise de problemas que procura atacar suas causas básicas. Essa iniciativa traz, consequentemente, lucros para as empresas (SIKILERO, RODRIGUES e LACERD, 2008).

O Sistema Toyota de Produção (STP) ou Lean Manufacturing, expressão pela qual este sistema produtivo se tornou conhecido no ocidente, enfatiza a redução de custos através da eliminação de desperdício. O Lean é formado por dois princípios direcionadores para facilitar este processo crítico, são eles: o Just in time (JIT) e o Jidoka (OHNO, 1997). O Lean Manufacturing é o melhor meio de fabricar produtos, e pode ser implantado em todo tipo de manufatura (VEIGA, LIMA e COSTA, 2008).

A Teoria das Restrições e o Lean Manufacturing possuem objetivos semelhantes. Ambas tendem a aumentar o lucro, o cliente é quem define o valor, ambas priorizam a qualidade, recomendam pequenos lotes de produção, ressaltam o fluxo contínuo e maior capacidade produtiva, bem como visam a redução de inventário (PACHECO, 2010). Segundo Moore e Scheinkopf (1998), as técnicas da TOC e do Lean Manufacturing na maioria das vezes se combinam.

Desta forma, esse trabalho tem por objetivo propor a integração da Teoria das Restrições (TOC) com o Lean Manufacturing. Essa junção será feita através da identificação das ferramentas do Lean Manufacturing, que poderão auxiliar no processo de implantação dos cincos passos da TOC. Como objetivos específicos, tem-se:

- Identificar com base na literatura as principais ferramentas do Sistema Toyota de Produção;

- Identificar com base na literatura a metodologia de implementação da TOC;

- Identificar quais ferramentas podem ser utilizadas em cada um dos 5 passos da TOC.

Este trabalho fará uso de um estudo bibliográfico. A partir de revisão de literatura as ferramentas Lean serão identificadas, e sua integração na implementação da TOC será proposta.

Este artigo está dividido em cinco seções. A primeira apresentou a introdução do trabalho, seus objetivos, justificativa e método de pesquisa. A segunda seção apresentará a revisão de literatura na qual se aborda os temas: TOC e Lean Manufacturing. Na terceira seção será apresentada a integração das ferramentas do Lean Manufacturing nos cinco passos da Teoria das Restrições. Na quarta seção será apresentada a conclusão, seguida pelas referências bibliográficas. 


\section{Revisão de Literatura}

\subsection{Teoria das Restrições}

A Teoria das Restrições (Theory of Constrations - TOC) surgiu na década de 70 quando Eliyahu Goldratt, físico Israelense, passava por problemas de logística de produção. Goldratt ficou inconformado com os métodos da administração da produção tradicionais não fazerem muito sentido, e inventou um novo método de administração da produção (GOLDRATT, 1990).

Esse método foi bem aceito, e surgiu interesse de várias empresas que queriam aprender a técnica. No começo dos anos 80, Goldratt escreveu o livro "A Meta", o livro foi escrito na forma de um romance e apresenta os obstáculos encontrados por um gerente na administração na empresa. Outros problemas começaram a surgir em outros setores da empresa. Goldratt solucionou os problemas das demais áreas, como logística de distribuição e gerenciamento de projeto. Quando a empresa utilizava as soluções que ele tinha inventado, ela se alavancava no mercado competitivo, porém, se estacionava. Vendo isso, Goldratt resolveu treinar as pessoas para resolverem tais problemas. Pois, em sua opinião, a empresa tinha que enfrentar e vencer seus próprios obstáculos e assim, prever seu futuro. No decorrer da história, o gerente descobre os princípios da teoria de Goldratt, e a organização consegue voltar a competitividade (GIUNTINI et al, 2002).

O livro obteve e mantém um grande sucesso. Várias empresas que adotaram a teoria de Goldratt obtiveram uma grande melhora (GIUNTINI et al, 2002).

A Teoria das Restrições destaca que as empresas funcionam como um sistema que tem seus altos e baixos, e podem até falir dependendo do caso em que se encontram. O futuro da empresa cabe a todos os elementos que nela trabalham, porque um elemento depende do outro de alguma maneira. Pode-se fazer a comparação do sistema com uma corrente, afirmando que sua performance vai ser sempre limitada pelo elo mais fraco. O que quer dizer que, leva em conta a quantidade de esforço ou recurso utilizado em uma empresa para um melhor processo, e para uma melhora no elo mais fraco. Propondo assim, uma melhora no sistema (HUBNER, 2005).

A restrição é tudo aquilo que pode, de alguma maneira, interferir no sistema, impedindo-o de atingir seu objetivo. A restrição pode assumir duas formas. São elas: físicas, tais como equipamentos e falta de material, ou de ordem gerencial, como procedimentos, políticas e normas (MOELLMANN et al, 2006).

O método de focalização da TOC consiste em cinco etapas, descrita a seguir (NETO, VILELA e SILVA, 2012):

1. Identificar as restrições: determinar qual parte do sistema está impedindo as empresas de atingir suas metas.

2. Explorar as restrições: este passo consiste em otimizar o uso das restrições. 
3. Subordinar: Nesse passo deve-se fazer a subordinação de qualquer coisa à decisão anterior, todas as atividades do sistema passam a ser subordinadas pela restrição encontrada no primeiro método.

4. Elevar as restrições: ocorre a concentração de esforços com o objetivo de elevar a quantidade de geração de saída da restrição.

5. Se alguma restrição passar despercebida deve-se voltar ao primeiro passo repetindo todo o processo até identificar uma nova restrição. (RODRIGUES e LACERDA, 2011).

Os cinco passos da TOC pode ser visualizada na Figura 1 (CORBETT NETO, 1996).

Figura 1 - Exemplo de figura

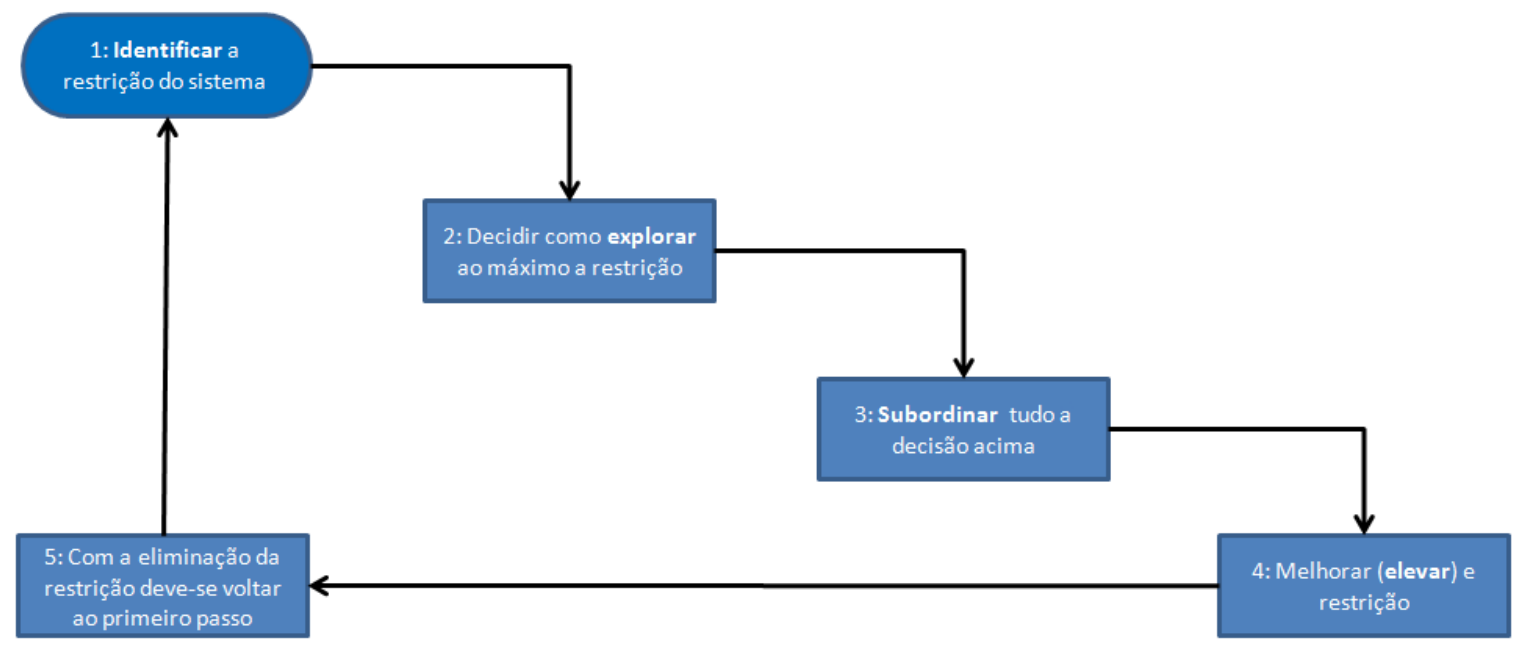

Fonte: Adaptado de Corbett Neto (1996)

Segundo Guerreiro (1996), a teoria das restrições consta de nove princípios básicos, são eles:

1. Balancear o fluxo e não a capacidade: A teoria das restrições faz advertências contra o balanceamento de capacidade, e defende o balanceamento do fluxo de produção na fábrica. Fazendo com que a ênfase priorize o fluxo de materiais e não priorize os recursos instalados. Tal ênfase só é possível através da identificação dos gargalos, tendo em vista a limitação do fluxo de todo o sistema. Essa abordagem prioriza a capacidade de recursos, com isso constata um fluxo calmo, contínuo na medida do possível.

\section{O nível de utilização de um recurso não gargalo não é determinado pelo seu próprio} potencial, e sim por uma outra restrição do sistema: Tal princípio destaca que a aplicação de um recurso não-gargalo é realizado em função das restrições existentes no sistema, por meio dos recursos internos, limitando a capacidade interna e também pelo mercado que pode causar essa limitação. 
3. A utilização e ativação de um recurso não são sinônimos: Esse princípio se forma através da distinção de dois conceitos, que são: utilização e ativação. A utilização equivale a aplicação de recursos não-gargalos, de acordo com a capacidade do recurso não gargalo. A ativação é adequada para uso de recursos não gargalos com volume maior que a do recurso gargalo. Essa ativação é o que basta para alimentar o recurso gargalo. A teoria das restrições tem como segundo enfoque a não contribuição da otimização. O fluxo (throughput) é contínuo, restringido pelo recurso gargalo, aumentando estoque e com isso as despesas operacionais. Tal princípio não se utiliza nas formas convencionais de produção.

\section{Uma hora perdida no gargalo é uma hora perdida no sistema inteiro: $O$ tempo no} gargalo é algo que não se deve desperdiçar, mesmo se o tempo for para preparação de máquinas, porque se desperdiçado pode causar alguns atritos e consequentemente agravação de alguns pontos importantes, tais como: diminuição do tempo restrito, que é disponibilizado para atender o volume throughput. Os recursos não gargalos tem seu fluxo estabelecido pelo gargalo, por isso devem trabalhar de forma balanceada. A redução do seu tempo causa uma redução do tempo de trabalho em todo o sistema. A redução dos setups nos recursos gargalos de produção só trazem benefícios. Com isso, a produção é programada com base nessa teoria, que é manter lotes maiores possíveis nos recursos gargalos. O tempo gasto com a preparação desses recursos deve ser minimizado e consequentemente isso aumentará a capacidade do fluxo.

5. Uma hora economizada em um recurso não gargalo é apenas uma ilusão: Como foi citado no item anterior, a economia de tempo é um fator importante na preparação das máquinas nos recursos gargalos. Porém, pode se obter através da redução de trocas de ferramentas (produzir lotes maiores), ou reduzir tempo de preparo (rapidez nas trocas). Sabendo que o ritmo de trabalho dos recursos não-gargalos é de acordo com o nível do gargalo, estes recursos serão inexistentes, ou seja, a economia elevaria o montante de tempo ocioso já existente.

6. Os gargalos governam o ganho e o inventário: os gargalos determinam o fluxo do sistema throughput ou ganho, e determinam os níveis dos estoques, procurando sempre evitar qualquer tipo de atraso, obtido por flutuações estatísticas ou por eventos aleatórios, que não agrave o gargalo, certificando da existência de um time buffer antes dos recursos gargalo. O time buffer nada mais é do que um tipo de estoque chamado de "estoque pulmão" por tempo de segurança.

7. O lote de transferência não pode, e muitas vezes não deve, ser igual ao lote de processamento: Lote de processamento equivale ao tratamento que esse lote vai ser processado em determinado recurso, já o lote de transferência é o tamanho do lote que é enviado para a próxima operação. No modelo da teoria das restrições não há necessidades dos lotes de processamento e de transferência serem iguais. Com isso há a possibilidade de dividir os lotes e reduzir tempos de passagem dos produtos de programação de produção. 
8. O lote de processamento deve ser variável e não fixo: todos os lotes devem ser o mesmo para todas as operações de fabricação do produto, fato assumido por todos pela maioria dos sistemas tradicionais. Isso leva a um problema na escolha do tamanho a ser adotado, levando em consideração características dessas operações individuais que podem conduzir a um cálculo diferente.

9. Os programas devem ser estabelecidos, considerando todas as restrições simultaneamente: Nesse item, a programação da produção deve levar em consideração o conjunto de restrições existentes ao responder questões de o quê, quanto e quando produzir. Nesse caso, observa-se o tratamento que foi exercido no lead time. O estabelecimento do lead time é dado através da programação do planejamento da produção.

\subsection{Sistema Toyota de Produção}

O Sistema Toyota de Produção (STP) teve sua origem no Japão, após a segunda guerra mundial na qual o país foi derrotado, inviabilizando a produção em massa devido a baixa produção do país e a falta de recursos (VEIGA, LIMA e COSTA, 2008).

O Sistema Toyota de Produção é também conhecido como Lean Manufacturing ou Produção Enxuta. Sendo desenvolvido pelo fundador da Toyota e mestre das invenções, Toyoda Sakichi e pelo engenheiro, Taiichi Ohno. A implantação do sistema vem sendo aplicada em várias empresas no mundo, porém nem sempre com sucesso (GODINHO FILHO e FERNANDES, 2004).

Todas as empresas possuem desperdício. Desperdício é tudo aquilo que não agrega valor ao produto. São eles: superprodução, transporte, processamento inapropriado, movimentos desnecessários, estoque, defeitos e espera (OKIMURA e SOUSA, 2012).

A eliminação desses desperdícios consiste no pensamento enxuto. Pensamento enxuto quer dizer fazer mais com menos. Menos esforço humano, menos equipamentos, menos tempo e menos espaço, e, além disso, oferecer aos clientes o que eles desejam (OHNO, 1997; WOMACK, JONES e ROSS, 1996).

\subsection{Principais Ferramentas do Lean Manufacturing}

Dentre as principais ferramentas do sistema Lean Manufacturing, destacam-se (WALTER e ZVIRTES, 2008):

Kanban: termo de origem japonesa que quer dizer "anotação visível". Através do kanban as pessoas envolvidas no sistema produtivo são informadas que devem produzir internamente (ELIAS e MAGALHÃES, 2003). 
Nivelamento da Produção: Esta ferramenta é também conhecida como Heijunka Box, seu objetivo é gerenciar visualmente e melhorar continuamente o processo, auxiliando os operadores na programação da produção (TARDIN e LIMA, 2000).

Segundo Menegon, Nazareno, Rentes (2003), produção nivelada é quando se consegue produzir em curtos intervalos de tempo os itens desejados. Fazendo isso se consegue atender os clientes rapidamente e produzir a quantidade certa sem excesso de produção.

Segundo Ghinato (1995), Heijunka é o nivelamento de pedidos através de uma programação nivelada das variações, para suprir a demanda a longo prazo, pode se dizer que Heijunka é quantidades de produtos niveladas.

Manufatura Celular: por meio dela a configuração do leiaute da fábrica é feita, levando em conta os postos de trabalho que fabricam produtos definidos, com sequencias e operações diferentes, com a finalidade de permitir o fluxo contínuo e a flexibilidade da mão-de-obra (ELIAS e MAGALHÃES, 2003).

5S: corresponde a cinco palavras japonesas, representando 5 sensos, voltados a manutenção de um ambiente produtivo limpo e saudável. São utilizadas para manter um local de trabalho adequado ao controle visual e a produção enxuta. Os 5S são compostos por (CAMPOS et al., 2005): Seiri: senso da utilidade; Seiton: senso de organização; Seiso: senso de limpeza; Seiketsu: senso de saúde e zelo; Shitsuke: senso de autodisciplina.

Setup rápido (SMED): essa ferramenta consiste em mostrar a necessidade da troca de ferramentas de maneira rápida, com o objetivo de que todos os produtos possam ser produzidos em pequenos lotes. Levando em conta as necessidades dos clientes de forma econômica (SHINGO, 2000).

Inspeção Autônoma: seu principal princípio é que qualidade não se controla, qualidade se faz. Quer dizer que, as inspeções devem ser feitas pelos próprios colaboradores, com o objetivo de eliminar a inspeção externa. Essa inspeção é feita pelo departamento de controle da qualidade. Como consequência, tem-se agilidade na produção (ELIAS e MAGALHÃES, 2003).

Manutenção Produtiva Total: parte do princípio que os próprios colaboradores possuem responsabilidade por parte da manutenção das máquinas que operam, com o objetivo de diminuir a requisição do departamento de manutenção. Diminuindo assim, a possibilidade do fluxo produtivo ser interrompido. É um termo crítico no Lean Manufacturing, porque trabalha com estoques tendendo a zero, possuindo dessa forma poucas possibilidades de manter a produção em andamento em caso de falhas (ELIAS e MAGALHÃES, 2003).

Dispositivo a prova de erro (Poka-yoke): tem com objetivo evitar a ocorrência de defeitos na produção. O poka-yoke possui duas maneiras nas quais ele pode ser usado para corrigir erros (ELIAS e MAGALHÃES, 2003): 
- Método de controle - quando o Poka-yoke é ativado se desliga a máquina ou a linha de processamento, para que o problema possa ser solucionado.

- Método de advertência - Nesse método o Poka-yoke assim que é ativado, pode ser notado através de sinalização de uma luz ou o soar de um alarme, alertando o trabalhador (SHINGO, 1996).

Gestão da Qualidade Total: É a realização de ação, na gestão de todos os recursos da organização, tais como o relacionamento das pessoas envolvidas nas empresas. Esta ação se torna consistente por meio de uma associação de ideias e técnicas, com o objetivo de aumentar a competitividade da empresa, especialmente as ideias que tem haver com melhoria de produto e processos (COLTRO, 1996).

Segundo Coltro (1996), a Gestão pela Qualidade Total está voltada para a satisfação do cliente seguindo um processo de melhoria contínua dos produtos e serviços oferecidos pela empresa. A gestão da qualidade total tem que ter controle sobre a qualidade, para que isso ocorra é necessário a participação de todos os integrantes da empresa, tais como gerentes, supervisores, trabalhadores e executivos, com o objetivo de melhorar continuamente.

Mapeamento do Fluxo de Valor (Value Stream Mapping): Rother e Shook (2003) consideram essa ferramenta de extrema importância, pois ajuda a enxergar muito mais do que os processos individuais. Todo o fluxo pode ser enxergado. O mapeamento aponta também as fontes de desperdícios. Dispõe de uma linguagem comum para tratar dos processos de manufatura, é visível o fluxo no qual se pode tomar decisões, acrescenta conceitos e técnicas enxutas, e com isso pode-se evitar a implementação de técnicas isoladamente.

Gestão Visual: De acordo com Walter e Zvirts (2008) esta ferramenta tem como seu principal objetivo utilizar controle visual, para que nenhum defeito passe despercebido.

A3: Segundo Sobek e Smalley (2008), o A3 se originou na Toyota com o objetivo de melhorar a capacidade de solução de problemas, tem esse nome por causa do tamanho do papel utilizado na sua elaboração. É uma ferramenta poderosa e impõe uma estrutura sólida para implantar a gestão de PDCA, e demonstra aos responsáveis uma compreensão mais aprofundada do problema para que este possa resolver o problema.

Kaizen: Pode se dizer que kaizen consiste em esforços de melhoria contínua, executados por todos tendo como objetivo principal a eliminação de desperdícios. Pode-se definir um evento Kaizen como uma equipe dedicada à implementação de uma ferramenta Lean em uma área em particular e em pouco tempo (ARAUJO e RENTES, 2006).

Trabalho Padronizado: É importante padronizar as tarefas para facilitar a identificação de problemas nos ambientes administrativos, dando origem a uma sequência eficiente para o fluxo de atividades, estabelecer melhores práticas e reduzir variações de procedimentos conservando um 
serviço de qualidade. O ideal é reduzir número de passos ou padronizar um processo, fazendo uma análise do fluxo de valor para frisar as atividades desnecessárias e grandes desperdícios (OLIVEIRA, 2008).

\section{Integração da Teoria Das Restrições ao Lean Manufacturing}

A Teoria das Restrições e o Lean Manufacturing são filosofias que vem recebendo muita atenção nos últimos anos por se tratarem de filosofias populares e por possuírem objetivos semelhantes. Há quem diga, no entanto, que não há espaço para as duas filosofias. Porém, existem trabalhos que consideram que as técnicas da TOC e do Lean na maioria das vezes possuem afinidades (MOORE e SCHEINKOPF, 1998).

As duas ferramentas adotam o princípio de controle do fluxo de produção por meio do mercado. As duas filosofias focalizam suas técnicas de melhorias para controlar o fluxo de material no chão de fábrica, promovendo a diminuição no estoque e nos prazos de entrega (MOORE e SCHEINKOPF, 1998).

O Lean Manufacturing focaliza o fluxo, com o objetivo de eliminar desperdícios que não agregam valor ao cliente, concedendo menor variação, maior qualidade, padronização e menores estoques. Na TOC, seu foco é a restrição do sistema. Pode-se obter melhores sistemáticas por meio do gerenciamento da restrição através da redução de inventários, possibilitando maiores ganhos (OKIMURA e SOUSA, 2012).

A TOC possui 5 passos para sua implantação no chão de fábrica (PERGHER, RODRIGUES e LACERD, 2011), este trabalho irá propor na sequências, as principais ferramentas do sistema Lean Manufacturing que podem auxiliar na implantação de cada um dos 5 passos da TOC.

\subsection{Aplicação de Ferramentas Lean para Identificar a Restrição}

O primeiro passo da TOC prioriza a identificar das restrições. Nesse primeiro passo relata-se a importância de identificar as possíveis restrições que de uma certa forma impedem a organização de atingir sua meta (PERGHER, RODRIGUES e LACERD, 2011).

Dentro deste primeiro passo do processo de focalização, pode-se destacar algumas ferramentas do Lean com objetivo de identificar as restrições.

1. Mapeamento do Fluxo de Valor: Ferramenta essencial ajuda a ter uma visão geral não somente de processos individuais, com ela pode-se enxergar o fluxo e destacar mais do que apenas desperdícios. O mapeamento de processo ajuda a identificar as fontes de desperdícios, com isso obtém-se uma linguagem comum para que se possa tratar os processos de manufatura (ROTHER e SHOOK, 2003). O Mapeamento do Fluxo de Valor fornece uma base na qual pode ser feita um plano de implementação do Lean, e nessa base de implementação é mostrada a relação entre o fluxo 
de informação e o fluxo de material (NAZARENO, RENTES, SILVA, 2001). Por meio dessa base pode ser identificada a restrição, através da marcação do ciclo de cada fase apresentada mapa.

2. Gemba: Termo japonês que quer dizer lugar verdadeiro, ou seja, lugar onde ocorre o trabalho que agrega valor ao produto. No processo de produção o Gemba é definido como local onde ocorre a transformação do produto, ou seja, chão de fábrica (SILVA et al, 2008). Na melhoria contínua, o Gemba tem por objetivo desenvolver trabalho em grupo para identificar os problemas e suas causas raízes, aplicando as ferramentas que convém e também propor soluções, aplicar melhorias, padronizar o processo e acompanhar os resultados para garantir a meta estabelecida (SILVA et al, 2008). Por ser uma ferramenta utilizada no chão de fábrica, pode se dizer que fica mais fácil de descobrir onde a restrição no processo produtivo se encontra por meio da observação na linha de produção, conversando com os funcionários, coletando as informações necessárias a identificação da restrição.

3. Gestão Visual: Essa ferramenta será adequada para identificar as restrições por ela utilizar controles visuais para identificar os defeitos, ela pode ser aplicada em quadros de controle. Esse quadro tem todas as rotas traçadas e serve para que o operador destaque onde ocorreu o problema na entrega de matéria-prima (NAZARENO, RENTES e SILVA, 2001).

\subsection{Aplicação de Ferramentas Lean para Explorar a Restrição}

O segundo passo da TOC prioriza a exploração da restrição. Esse passo visa a importância de se promover a otimização do uso da restrição (PERGHER, RODRIGUES e LACERD, 2011).

A grande ideia do Lean Manufacturing é fazer mais com menos, essa é a mesma ideia que se aplica para explorar a restrição, aplicando ferramentas Lean. Para a execução desse passo identificou-se as seguintes ferramentas: A3 (demonstrar soluções para resolução de problemas e que a chance do problema voltar a acontecer seja mínima), 5S (organizar o ambiente de trabalho e motivar os funcionários), Gestão visual, Trabalho Padronizado (para abordar as melhores práticas de trabalho), Kaizen (discussão e implementação de ideias incrementais para melhoria).

1. A3: É mais do que uma folha de papel, essa ferramenta obriga os envolvidos a observarem a realidade, pode também destacar fatos, propondo medida de trabalho com objetivo de cumprir a meta determinada (SOBEK e SMALLEY, 2008). Ela pode destacar onde se encontra as restrições do sistema produtivo e quais os diagnósticos que podem ser aplicados. Sua aplicação leva a um entendimento mais profundo do problema, ela também elabora novas ideias para que possa ser implantada com o objetivo de sanar o problema explorando a restrição.

2. 5S: essa ferramenta resume-se basicamente em demonstrar a dedicação das pessoas em organizar o local de trabalho, por meio de ações como: limpeza, padronização e disciplina na realização do trabalho. Pode se dizer que o 5S é uma grande faxina. Ele examina três dimensões 
básicas. São elas: física (layout), intelectual (realizações de tarefas) e social (relacionamento de ações do dia-a-dia). As três dimensões dependem uma das outras. Quando acontece uma melhora ou qualquer outra mudança em uma das dimensões sente-se o reflexo nas outras. O 5S exige uma profunda transformação, mas, para que isso possa ocorrer é necessário o empenho de todos, vontade de mudar, e também participação da alta gerência, que é crucial para que se possa espalhar os novos hábitos (CAMPOS et al,2005). O 5S verifica o sistema produtivo, analisando-o e eliminando o que não é necessário, organizando e limpando. Com o ambiente de trabalho mais organizado e limpo ficará mais fácil explorar a restrição do sistema.

3. Gestão Visual: Como essa ferramenta tem por ideia principal o controle visual para que não se passe nenhum problema despercebido se aplicado, para explorar a restrição, será ideal para que fique constatado que realmente não há mais restrição (NAZARENO, RENTES e SILVA, 2001).

4. Trabalho Padronizado: constitui em designar e documentar o procedimento que dá o resultado adequado, utilizando métodos e sequências das atividades, da melhor maneira possível. As tarefas padronizadas são uma importante ferramenta para identificar problemas nos setores administrativos. Com isso, cria-se uma sequência para o fluxo de atividades, diminuindo a variabilidade nos procedimentos, instalando as melhores práticas para manter a qualidade de serviço, treinando os colaboradores de forma simples para que eles possam fazer mais de uma função, e priorizando o fluxo. Deve-se fazer redução do número de passos. Procura-se minimizar o número ao prodronizar um processo, observando o fluxo de valor para ressaltar as tarefas desnecessárias e desperdícios inerentes a elas (OLIVEIRA, 2008). O que se vê nessa ferramenta é que ela pode ser aplicada para explorar a restrição e trazer grandes benefícios para a organização porque ela traz consigo uma grande bagagem de informações do processo. De acordo com Walter e Zvirtes (2008), essa ferramenta é de grande importância porque descreve as atividades práticas de cada trabalho com informações, tais como: tempo de ciclo, takt time, e a quantidade de estoque minimo para realizar a atividades. Aplicando essa ferramenta pode-se dessa forma explorar a restrição do sistema.

5. Kaizen: é uma ferramenta que seu principal objetivo é desenvolver trabalho em grupo com a finalidade de localizar problemas e suas causas raízes com a utilização de ferramentas adequadas, ele também propõe soluções, aplica melhorias e padroniza os processos (SILVA et al, 2008). No combate a restrição do sistema produtivo por ser uma ferramenta que está ligada com o chão de fábrica fica mais fácil de identificar e obter informações a respeito do processo produtivo. Dessa forma com a aplicação de melhorias no chão de fábrica pode-se explorar a restrição. 


\subsection{Aplicação de Ferramentas Lean para Subordinar a Restrição}

O terceiro passo da TOC visa subordinar todas as atividades do sistema à restrição que foi encontrada no primeiro passo (PERGHER, RODRIGUES e LACERD, 2011). Algumas técnicas de manufatura enxuta podem ajudar e muito na hora de subordinar as restrições, principalmente técnicas utilizadas para regular o fluxo produtivo (kanban) e sincronizar as linhas de produção.

1. Kanban: essa ferramenta é uma técnica de gestão de materiais e de produção, é um método que puxa as necessidades de produtos acabados, se diferencia do método de produção tradicional que empurra. É um método simples de autocontrole no nível de fábrica (HINSCHINK e NEUMANN, 2007). Dentro dos passos da TOC, o kanban oferece técnicas visuais que servem para controlar o fluxo de materiais, com isso se ocorrer algum problema sabe-se onde este se encontra.

2. Nivelamento de Produção: orienta os colaboradores a fazerem a programação da produção controlando estoque de peças produzidas, além da quantidade que deve se produzir, muitos produtos são produzidos na linha, mas o ritmo e horário é ditado por essa ferramenta (MENEGON, NAZARENO e RENTES, 2003). É uma importante arma para que se possa combater a restrição, porque essa ferramenta destaca que deve se produzir todos os produtos em pequenos intervalos, fazendo isso consegue-se atender o cliente no ritmo definido por ele ou pela restrição.

\subsection{Aplicação de Ferramentas Lean para Elevar a Restrição}

O quarto passo da TOC prevê a elevação da restrição. Nesse passo deve ocorrer a concentração de esforços com o objetivo de aumentar a capacidade de geração de saída da restrição (PERGHER, RODRIGUES e LACERD, 2011). Ferramentas que possuem aplicações diretas na restrição são: TPM, SMED, Poka-Yoke e o Jidoka.

1. TPM (Manutenção Produtiva Total): Exige que os colaboradores façam a manutenção das máquinas na qual trabalham, com isso diminui a dependência do departamento de manutenção, e também diminui as chances de se interromper o processo produtivo, porque essa ferramenta trabalha com estoque tendendo a zero (ELIAS e MAGALHÃES, 2003). Se o próprio operador faz a manutenção de sua máquina, ganhasse tempo, uma vez que este não precisa ficar esperando o pessoal do departamento de manutenção, e consequentemente evita-se ficar com máquina parada.

2. SMED: Sua finalidade é reduzir o tempo de setup em máquinas ou equipamentos que necessitam de trocas de ferramentas ou materiais, e por isso, tenha que ser desligada para que ocorra a troca (CABRAL e ANDRADE, 1998). Com essa ferramenta a restrição pode ser elevada, uma vez que se diminui o tempo envolvido na troca de ferramentas.

3. Poka-Yoke: tem o objetivo de eliminar defeitos na produção. Ele pode ser usado para corrigir erros. Essa ferramenta é muito importante porque reduz defeitos, e com a redução de 
defeitos, eleva a restrição do sistema produtivo. Também permite que o operador possa fazer outro serviço enquanto a máquina opera e só se deslocar até ela se esta sinalizar.

4. Jidoka: Também conhecido com Autonomação. Muitas vezes é referida como "automação com toque humano" permite que o operador ou a máquina parar sempre que for detectada alguma irregularidade no processo. Essa ferramenta surgiu na Toyota com objetivo de fazer com que o operador possa trabalhar em mais de uma máquina, com o objetivo de aumentar a eficiencia e a produção. No STP é extendida para a aplicação em linhas de produção desenvolvida manualmente, com isso o operador pode desativar a máquina sempre que notar alguma irregularidade (GHINATO, 1995). Por ser uma ferramenta cuja idéia central é eliminar a propagação de defeitos ao mesmo tempo que permite o aumento de produtividade e o aumento da utilização do operador ela é de extrema importância para o combate a restrição.

\subsection{Aplicação de Ferramentas Lean para o Quinto Passo da TOC}

O quinto passo de focalização funciona como se fosse um ciclo de melhoria contínua. Se a restrição for eliminada deve-se trabalhar na restrição seguinte. Esse passo visa demonstrar a importância de não deixar a inércia tornar-se uma restrição do sistema. Esse tópico ressalta a grande importância de rever todo o sistema, quando ocorrer o aumento de capacidade da restrição, uma vez que, com o aumento obtido a restrição do sistema pode passar a ser outro recurso que antes não era.

As 3 ferramentas destacadas no item 3.1 podem ser aplicadas novamente nesta etapa, no entanto destaca-se a seguinte ferramenta para ser aplicada neste ultimo passo da TOC:

1. Mapeamento do Fluxo de Valor (VSM): Ferramenta que disponibiliza uma visão geral do sistema e de todas as etapas percorridas pelo produto até chegar ao cliente, tal como o fluxo de material e informação (MOREIRA e FERNANDES, 2001). O VSM possui duas versões, o mapa do estado atual e o mapa do estado futuro. O mapa do estado futuro é especialmente útil para o quinto passo da TOC, uma vez que registra um estado com a aplicação de todas as melhorias visualizadas para o sistema.

\section{Conclusão}

Este artigo apresentou duas ferramentas de extrema importância para as empresas que buscam a redução de desperdício e a gestão de desperdícios a Teoria das Restrições e o Lean Manufacturing. Ambas as metodologias podem ser aplicadas por empresas de todos os tamanhos.

O trabalho identificou a forma de implantação da TOC, por meio dos seus 5 passos, bem como as principais ferramentas do Sistema Lean Manufacturing. Com a realização da revisão de literatura pode-se identificar quais ferramentas do sistema Lean Manufacturing poderiam auxiliar 
na implementação de cada um dos passos da TOC. Com este trabalho é possível afirmar que as duas ferramentas podem ser grandes aliadas contribuindo para o sucesso de qualquer organização.

Como trabalho futuro sugere-se a realização de um estudo de caso envolvendo a aplicação da TOC em um ambiente industrial, auxiliado pelas ferramentas Lean identificadas neste trabalho.

\begin{abstract}
This work will be discussed problems faced daily in business, caused by waste and bottlenecks in production systems. The presence of restrictions and prevent waste, in many cases, companies achieve their goals. In this situation, two methodologies of great importance to the business and used by Production Engineering success, can be used to combat these limitations: the Theory of Constraints and Lean Manufacturing. When used in a joint way they allow eliminate waste in the system, as well as effectively manage the constraints causing businesses to achieve their goals. In this work, a literature review will be conducted, identifying which tools of Lean Manufacturing could assist in the implementation of each step of the Theory of Constraints. In this work, it can be concluded that both production philosophies have common points, and they contribute to the business success of an organization when used together.
\end{abstract}

Key-words: Theory of Constraints; Lean Manufacturing; Lean Tools; waste; Integration.

\title{
Referências
}

ARAUJO, C. A. C.; RENTES, A. F. A metodologia Kaizen na condução de processos de mudança em sistemas de produção enxuta. Revista Gestão Industrial, v.2, n.2, 2006. crossref

CABRAL, R. H.; ANDRADE, R. S. Aplicabilidade do Pensamento Enxuto. Anais... Encontro Nacional de Engenharia de Produção, 1998.

CAMPOS, R.; OLIVEIRA, L. C. Q.; SILVESTRE, B. S.; FERREIRA, A. S. A ferramenta 5S e suas implicações na gestão da qualidade total. Anais... Simpósio de Engenharia de Produção, 2005.

CORBETT NETO, T. Uma comparação entre "Activity-Based Costing” e Teoria das Restrições, no contexto da contabilidade gerencial. Dissertações de Mestrado em Administração de Empresas. Escola de Administração de Empresas de São Paulo (EAESP), São Paulo, 1996.

COLTRO, A. A Gestão da Qualidade Total e suas influências na competitividade empresarial. Caderno de pesquisas em administração, São Paulo, v.1, n.2, p.1-7, 1996.

ELIAS, S.J.B.; MAGALHÃES, L.C. Contribuição da produção enxuta para obtenção da produção mais limpa. Anais... Encontro Nacional de Engenharia de Produção, 2003.

GODINHO FILHO, M.; FERNANDES, F.C.F. Manufatura Enxuta : Uma revisão que classifica e analisa os trabalhos apontando perspectivas de pesquisas futuras. Gestão e Produção, v.11, n.1, p.1-19, 2004. cross ref

GHINATO, P. Sistema de Produção: Mais do que Simplesmente Just-in-time. Revista Produção, v. 5, n. 2, p. 169-190, 1995.

GIUNTINI, N.; PIZOLATO, C. D. L.; XAVIER, J. S.; DI GIORGIO, W. A. B. Teoria das restrições: uma nova forma de "ver e pensar" o gerenciamento empresarial, Faculdade de Ciências Econômica de São Paulo, 2002.

GOLDRATT, E. M. Theory of constraints. Croton-on-Hudson, NY: North River, 1990.

GUEREIRO, R. Os princípios da Teoria das Restrições sob a ótica da mensuração econômica. Caderno de Estudos, n.13, p.1-10, 1996. 
HINSCHINK, S. F.; NEUMANN, M. L. Aplicação do Sistema Kanban no setor de fundição de Magnésio da Empresa Stihl. Feevale, 2007.

HUBNER, R. B. Enfoque gerencial na contabilidade de custos: como aumentar o ganho sem diminuir despesas operacionais utilizando a teoria das restrições. Anais... Congresso Virtual Brasileiro de Administração, 2005.

MENEGON, D.; NAZARENO, R. R.; RENTES, A. F. Relacionamento entre desperdícios e técnicas a serem adotadas em um sistema de produção enxuta. Anais... Encontro Nacional de Engenharia de Produção, 2003.

MOELlmANN, A. H.; ALBUQUERQUE, A. S.; CONTADOR, J. L.; MARINS, F. A. S. Aplicação da teoria das restrições e do indicador de eficiência global do equipamento para melhoria de produtividade em uma linha de fabricação. Revista Gestão Industrial, v.2, n.1, 2006. crossref

MOORE, R.; SCHEINKOPF, L. Theory of Constraints and Lean Manufacturing: Friends or Foes? Chesapeake Consulting, Inc. 1998.

MOREIRA, M.P.; FERNANDES, F. C. Avaliação do Mapeamento do Fluxo de Valor como Ferramenta da Produção Enxuta por Meio de um Estudo de Caso. Anais... Encontro Nacional de Engenharia de Produção, 2001.

NAZARENO, R. R.; RENTES, A. F.; SILVA, A. D. Implantando Técnicas e Conceitos da Produção Enxuta Integradas à dimensão de Análise de Custos. Anais... Encontro Nacional de Engenharia de Produção, 2001.

OLIVEIRA NETO, A. F.; VILELA, M. S. S.; SILVA, M. A. Gestão dos fatores restritivos em indústria alimentícia de pequeno porte: aplicação dos conceitos da Teoria das Restrições. Anais... Simpósio de Excelência em Gestão e Tecnologia, 2012.

OLIVEIRA, J. D. Escritório enxuto (Lean Office). Lean Institute Brasil, 2008.

OHNO, T. O sistema Toyota de Produção - Além da produção em larga escala. Porto Alegre: Bookman, 1997.

OKIMURA, L. I.; SOUSA, F. B. Análise dos modelos de integração das abordagens teoria das restrições, produção enxuta e seis sigma: um estudo teórico. Anais... VIII Congresso Nacional de Excelência em Gestão, 2012.

PACHECO, D. A. J. A proposição de estratégias para elevar a capacidade das restrições em sistemas produtivos: a aplicação integrada da teoria das restrições e do Lean Manufacturing. Anais... Encontro Nacional de Engenharia de Produção, 2010.

PERGHER, I.; RODRIGUES, L. H.; LACERD, D. P. Discussão teórica sobre o conceito de perdas do Sistema Toyota de Produção: inserindo a lógica do ganho da Teoria das Restrições. Gestão e Produção, v.18, n.4, p.673-686, 2011. crossref

ROTHER, M.; SHOOK, J. Aprendendo a enxergar. São Paulo: Lean Institute Brasil, 2003.

SHINGO, S. O Sistema de Troca Rápida de Ferramentas. Porto Alegre: Editora Bookman, 2000.

SHINGO, S. O Sistema Toyota de Produção: do ponto de vista da engenharia de produção. Porto Alegre: Editora Bookmann, 1996.

SIKILERO, C. B., RODRIGUES, L. H.; LACERDA, D. P. Análise crítica das soluções da teoria das restrições para o gerenciamento da cadeia de suprimentos: uma análise teórica. Anais... Encontro Nacional de Engenharia de Produção, 2008.

SILVA, G.G.; HORNBURG, S.; TUBINO, D.F.; ROMIG, M.; ANDRADE, G.J. Manufatura enxuta, Gemba Kaizen e TRF: Uma aplicação prática no setor têxtil. Anais... Encontro Nacional de Engenharia de Produção, 2008.

SOBEK, D.K.; SMALLEY, A. Understanding A3 Thinking: A critical element of Toyota's PDCA management system. Boca Raton: CRC Press, 2008.

TARDIN, G.G.; LIMA, P.C.L. O papel de um quadro de nivelamento de produção na produção puxada: um estudo de caso. Anais... Encontro Nacional de Engenharia de Produção, 2000.

VEIGA, G. L.; LIMA, E.; COSTA, S. Escolhas estratégicas na produção enxuta. Anais... Encontro Nacional de Engenharia de Produção, 2008. 
WALTER, O. M. F. C.; ZVIRTES, L. Implantação da produção enxuta em uma empresa de compressores de ar. Anais... Encontro Nacional de Engenharia de Produção, 2008.

\section{Dados dos autores}

\section{Nome completo: Geovanni Geraldo da Silva}

Filiação institucional: Centro Universitário de Itajubá

Departamento: Curso de Engenharia de Produção

Função ou cargo ocupado: Aluno graduado

Endereço completo para correspondência: Rua Doutor Antônio Braga Filho, 687, Bairro Varginha, Itajubá - Minas Gerais - CEP 37501-002

Telefone: (35) 3629-8400

e-mail: geovannisilva707@yahoo.com.br

Nome completo: Rafael de Carvalho Miranda

Filiação institucional: Centro Universitário de Itajubá

Departamento: Curso de Engenharia de Produção

Função ou cargo ocupado: Professor

Endereço completo para correspondência: Rua Doutor Antônio Braga Filho, 687, Bairro Varginha, Itajubá - Minas Gerais - CEP 37501-002

Telefone: (35) 3629-8400

e-mail: mirandaprod@yahoo.com.br

\section{Submetido em: 19/06/2014}

Aceito em: 18/12/2014 